\title{
Framework for Defining and Assessing Benefits of a Modular Assembly Design Approach for Exploration Systems
}

\author{
John T. Dorsey ${ }^{1}$, Timothy J. Collins ${ }^{2}$, Rud V. Moe ${ }^{3}$, William R. Doggett ${ }^{4}$ \\ ${ }^{1}$ Metals and Thermal Structures Branch, MS 396, NASA Langley Research Center, Hampton VA, 23681 \\ ${ }^{2}$ Mechanics of Structures and Materials Branch, MS 190, NASA Langley Research Center, Hampton VA, 23681 \\ ${ }^{3}$ Hubble Space Telescope Development Proj., Code 442, NASA Goddard Spaceflight Center, Greenbelt MD, 20771 \\ ${ }^{4}$ Dynamic Systems and Controls Branch, MS 308, NASA Langley Research Center, Hampton VA, 23681
}

(757) 864-3108; john.t.dorsey@nasa.gov

\begin{abstract}
A comprehensive modular assembly system model has been proposed that extends the art from modular hardware, to include in-space assembly, servicing and repair and it's critical components of infrastructure, agents and assembly operations. Benefits of modular assembly have been identified and a set of metrics defined that extends the art beyond the traditional measures of performance, with emphasis on criteria that allow life-cycle mission costs to be used as a figure of merit (and include all substantive terms that have an impact on the evaluation). The modular assembly approach was used as a basis for developing a Solar Electric Transfer Vehicle (SETV) concept and three modular assembly scenarios were developed. The modular assembly approach also allows the SETV to be entered into service much earlier than competing conventional configurations and results in a great deal of versatility in accommodating different launch vehicle payload capabilities, allowing for modules to be pre-assembled before launch or assembled on orbit, without changing the space vehicle design.
\end{abstract}

Keywords: Modular assembly, in-space assembly, servicing, repair, evaluation criteria, metrics, interfaces.

PACS: 89.75.-k

\section{INTRODUCTION}

A review of exploration missions and architectures indicates that many, or most of the vehicles, platforms and systems are large-area, massive and cannot be placed in orbit in a single launch using any existing, or projected launch vehicle (Troutman, 2002). In order to achieve the final mass, size and complexity of many of these future space systems, it will be necessary to incorporate the use of multiple launches and some degree of on-orbit assembly into their design. Also, in order to achieve an affordable and sustainable exploration program, it will be imperative to design systems that are modular, have long lifetimes and can be reused. Thus, the ability to inspect and detect faults, perform routine maintenance, repair and resupply and perform system upgrades becomes a necessary capability.

The goal of modularity is to simplify space-platform design by developing versatile repeating units that have a range of common features and interfaces. For maximum benefit and when possible, the modular units should be nonmission specific, allowing for commonality even between spacecraft having different mission architectures. Modularity reduces mission risk, and allows spares and replacements to be available during system assembly. The same modules used for initial construction can be used later if servicing or repair become necessary. A suite of available modules can provide the building blocks for a variety of spacecraft, allowing rapid development and deployment of new missions at substantially reduced costs. Modularity potentially enables reconfiguration and upgrading through the exchange of existing modules with new modules having different or improved functionality. Modularity, together with a robust capability to perform in-space assembly have the potential to greatly expand what is possible for NASA's exploration vision. Modularity can benefit space systems that do not incorporate any on-orbit 
assembly, servicing and repair operations, as described in Esper (2005) and Enright (1998). Additional benefits accrued by allowing for and incorporating the capabilities for on-orbit operations have not previously been addressed for many reasons, including lack of access to systems once in orbit (Enright, 1998), and lack of infrastructure and agents to perform in-space operations. To date, the benefits of modular design remain largely unsubstantiated, with many claimed and perceived benefits. However, few of these have been examined by appropriate systems analyses or validated through actual hardware and assembly test programs.

The reasons for the disparity between perceived and demonstrated benefits are many. To begin with, even the definition of modularity lacks consensus. At one extreme, a module can be a very large pre-integrated unit that only requires a single interface to neighboring modules. At the opposite scale, modular units can be much smaller, incorporating only subsystem functions, or in some cases individual pieces of repeatable structure that are assembled to form a larger system. Clearly, a modular hierarchy exists of increasing complexity, and it is necessary to appropriately optimize the level or degree of modularity for different applications. A related issue stems from a lack of consensus with regard to evaluation criteria for various modular structures and modular assembly approaches. No standard criteria or benchmarks exist to discriminate between the variety of proposed modular concepts and assembly approaches.

The research described in this paper has three objectives and is part of a larger project described by Collins (2006a). First is to define a Modular Assembly System Model. This model includes a hierarchical framework for defining levels of modularity, and defines attributes that allow one to distinguish modular from non-modular systems. The second objective is to define a comprehensive set of possible system benefits that extends the art to include in-space assembly, servicing and repair. Especially important is to include those benefits associated with affordability, sustainability and risk reduction, that can accrue by invoking a modular assembly approach. This also includes defining appropriate metrics for all of the attributes that can be used to rank modular systems and assess benefits. The third objective is to apply the model to a Solar Electric Transfer Vehicle (SETV) concept, define 3 levels of modular assembly and illustrate application of the metrics.

\section{MODULAR ASSEMBLY HIERARCHY SYSTEM MODEL}

This section describes the three major contributors to the modular assembly hierarchical system model; the four components that make up a modular system, a hierarchical framework for defining and organizing modular systems, and potential benefits that can be accrued in modular assembly systems.

\section{Modular Assembly System Components}

The modular assembly design approach is significantly more complex than simply the design of repeating and versatile units. The complete and comprehensive modular assembly system-of-systems encompass all of the following systems: 1) the mission-level (power platform, habitat complex, telescope) system that utilizes the modules and the associated module specifications and designs; 2) the agents that assemble, service and repair the modular subsystems (robots or astronauts); 3) the operations, and associated planning, required during assembly (positioning, aligning, joining), servicing and repair; and 4) the infrastructure (jigs, restraint and load reaction devices, cranes, mobile platforms, etc.) required to facilitate operations and enhance agent capabilities. All of these systems must be considered, defined and designed simultaneously in order to develop a specific mission architecture incorporating modularity and assembly that maximizes the benefits that can be accrued. The approach can be applied to in-space, as well as surface-based exploration systems, as shown in figures $1 \mathrm{a}$ and $1 \mathrm{~b}$ respectively.

\section{Hierarchical Framework}

A Modular System is composed of a number of modular sub-systems, including structures, power, propulsion, etc. When assembled, the systems modules form a Modular Spacecraft. Clearly, modularity can be considered in a hierarchical context, and can exist at many different levels in a complete spacecraft system. In figure 2, a hierarchical model is proposed for modular space systems. 


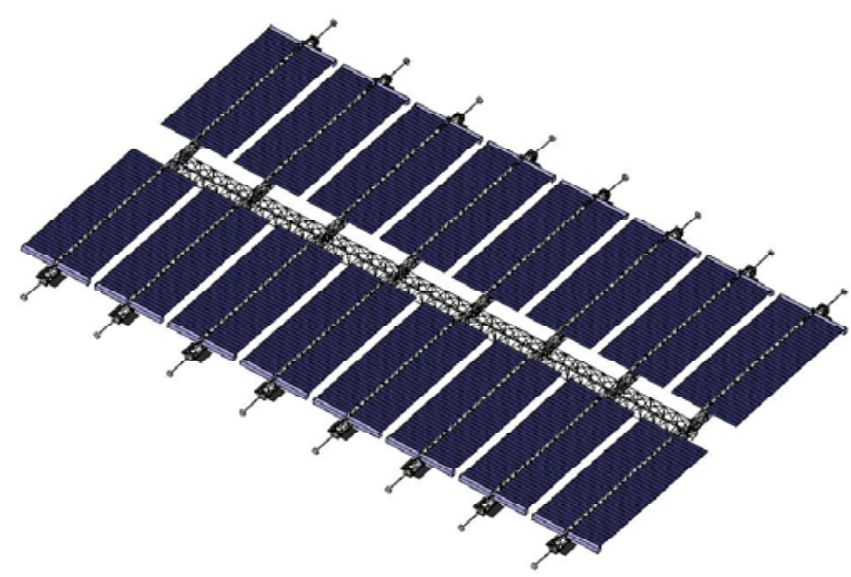

(a) Modular SETV.

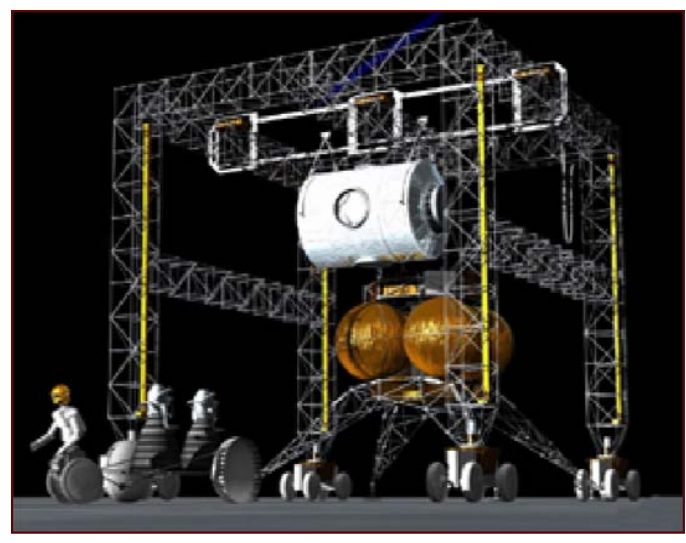

(b) Modular planetary surface infrastructure.

FIGURE 1. Examples of Modular Space Systems.

\section{Hierarchy Level}

Module

Sub-Module

Component

Sub-Component

\section{System Name: Parts}

$\Sigma$ Modules
Assemble \& Integrate

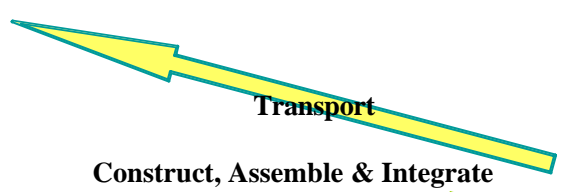

$\Sigma$ Sub-Modules
System-of-System: Aggregate

Spacecraft, Space

System or

Space Platform

Modules

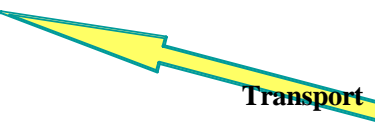

Construct \& Integrate

$\Sigma$ Components

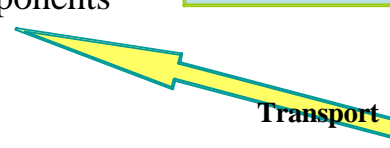

Construct \& Integrate

$\Sigma$ Sub-Components

\section{Components}

FIGURE 2. Modular Hierarchy System Model.

The number of levels in this model is not constrained. At each hierarchy level, it is assumed that a number of system parts are assembled and integrated to form an aggregation or system-of-systems. Definitions for a particular hierarchy level, and the System and System-of-System names associated with each level are also proposed in the model. For example, the highest aggregate system-of-systems level is the spacecraft or space platform, where modules are assembled and integrated to form the spacecraft. Similarly, for the next level down in the hierarchy, sub-modules are assembled to form modules. Assembly and integration requires a site for the operations to take place, a definition of the assembly operations and procedures, agents to perform the assembly functions, and supporting infrastructure. Depending on the scale of the spacecraft or space platform, the location for this assembly and integration could be on orbit (the International Space Station (ISS) for example), on the Earth (Geosynchronous Communications Satellites (GEO ComSats) for example), or on a planetary surface (a Lunar or Mars surface habitat for example). The agents include both humans, in either Extra-Vehicular and/or Intra-Vehicular Activity (EVA and 
IVA), and robots, either teleoperated or autonomous. The infrastructure could include a facility or platform dedicated to assembly, including cranes, fixtures, environmental control and protection, power, etc. For the Advanced Materials and Structures for the Modular Assembly of Large Space Platforms (MALSP) project described in Collins (2006a), the assembly site for the module level is assumed to be on orbit. However, the definitions and considerations for modularity discussed here are likely to have broad applicability, that in many cases will extend to surface-based Exploration Systems such as those planned for the Moon or Mars (see figure 1b). Many of the considerations are likely relevant to Earth-based applications as well.

\section{Attributes and Definitions}

In general, previous modularity definitions capture all of the sub-attributes associated with standardization in Table 1. However, they do not consider or address modularity sub-attributes associated with Versatility and Maintainability. This paper attempts to define a more comprehensive set of modularity attributes by expanding previous definitions to include those resulting from on-orbit operations, so that the resulting benefits to system life cycle costs can be captured and assessed. The resulting list of modular attributes, associated Sub-Attributes and their definitions and descriptions are compiled in Table 1.

TABLE 1. Modular Attributes.

\begin{tabular}{|l|l|l|}
\hline \multicolumn{1}{|c|}{ Attribute } & \multicolumn{1}{|c|}{ Sub-Attribute } & \multicolumn{1}{c|}{ Description, Comment } \\
\hline Standardization & Standard Interfaces & For mechanical, fluid, electrical, etc. connections \\
\hline & Standard Modules & $\begin{array}{l}\text { Standard modules for spacecraft hardware components, on-orbit } \\
\text { infrastructure (including tools), and on-orbit robotic agents }\end{array}$ \\
\hline & $\begin{array}{l}\text { Discrete Performance } \\
\text { Levels }\end{array}$ & $\begin{array}{l}\text { Sets of standardized components with discrete levels of } \\
\text { performance or capability, and components are validated and } \\
\text { available off-the-shelf (features design heritage) }\end{array}$ \\
\hline & Plug and Play & $\begin{array}{l}\text { Allows for hardware changes and additions without the need for } \\
\text { any redesign }\end{array}$ \\
\hline Versatility & $\begin{array}{l}\text { Only form, fit and function } \\
\text { specified }\end{array}$ & $\begin{array}{l}\text { Encapsulated functionality decouples sub-systems from each } \\
\text { other (Enright, 1998) }\end{array}$ \\
\hline & $\begin{array}{l}\text { Accommodate variety of } \\
\text { launch vehicle packaging } \\
\text { options }\end{array}$ & $\begin{array}{l}\text { Can readily be packaged on launch vehicles with different } \\
\text { payload mass and volume capabilities }\end{array}$ \\
\hline & $\begin{array}{l}\text { Reconfigurable on orbit for } \\
\text { new mission or application }\end{array}$ & $\begin{array}{l}\text { Modular components can be disassembled and recombined for a } \\
\text { new mission or spacecraft }\end{array}$ \\
\hline & $\begin{array}{l}\text { Capability for disassembly } \\
\text { and reassembly }\end{array}$ & Operations performed in-situ: in space or on planetary surfaces \\
\hline Upgradeable & Enhanced capability, or insertion of new technology \\
\hline $\begin{array}{l}\text { Maintainability (in space, } \\
\text { planetary surfaces) }\end{array}$ & Serviceable & $\begin{array}{l}\text { Growable: part count changes (each part doesn't change), } \\
\text { replications added (add modules to grow power production or } \\
\text { fuel storage capacities for example, can be incremental) } \\
\text { Scalable: part count stays the same, but the size or dimensions } \\
\text { change }\end{array}$ \\
\hline & Repairable & Fluid replenishment and regular (scheduled) maintenance \\
\hline
\end{tabular}

\section{BENEFITS OF MODULAR ASSEMBLY}

Technologies and hardware that result in, or contain a high degree of modularity are anticipated to enable affordable large space structures, space systems and spacecraft, resulting in sustainable exploration missions. Modularity also has the potential to reduce program and mission risk, as well as increase system performance (less mass for example). A brief history of past modular spacecraft programs and their results are summarized in Esper (2005). Although modularity has been successfully incorporated into spacecraft that are launched as a single entity (GEO ComSats for example), it is anticipated that much greater benefits to system affordability and sustainability will be incurred for Exploration spacecraft and platforms that must be assembled on orbit. Given the large sizes and masses of many of the Exploration mission spacecraft, multiple launches will be required to place the systems in orbit, with some amount of on-orbit construction, assembly and system verification required to place the spacecraft into service. Modularity, by naturally encompassing the capability for servicing and repair improves the possibilities for affordability and sustainability. 
Benefits are the advantages to a system or system-of-systems that result from adopting the attributes of modularity. Benefits of modularity can be accrued for the case where multiple launches of modules, along with on-orbit assembly is used to build a spacecraft or space platform. In addition, the benefits can accrue for all elements in the full system of systems; the spacecraft modules, the on-orbit infrastructure, and the agents and their supporting systems. These have been compiled in the broad categories of performance, cost and risk and are given in Table 2 .

TABLE 2. Benefits Accrued Due to Modular Assembly.

\begin{tabular}{|c|c|c|c|}
\hline \multirow[t]{2}{*}{ Attribute } & \multicolumn{3}{|c|}{ Benefits } \\
\hline & Performance In Service & Life Cycle Cost & Life Cycle Risk \\
\hline \multicolumn{4}{|l|}{ Standardization } \\
\hline Standard Interfaces & & $\begin{array}{l}\text { - Increases servicing efficiency } \\
\text { - Reduces design, development } \\
\text { and validation cost }\end{array}$ & $\begin{array}{l}\text { - Common, repetitive and } \\
\text { validated operations lower risk }\end{array}$ \\
\hline Standard Modules & $\begin{array}{l}\text { - Non-optimized systems may } \\
\text { have higher margins of safety } \\
\text { - Minimize total system or } \\
\text { architecture mass when } \\
\text { standard modular infrastructure } \\
\text { and agents used }\end{array}$ & $\begin{array}{l}\text { - Reduce design, development } \\
\text { and verification costs } \\
\text { - Cost decrease as more } \\
\text { produced, i.e. becomes off-the- } \\
\text { shelf or commodity } \\
\text { - Focus resources on items } \\
\text { requiring optimized design } \\
\text { - Reduced costs as applied to } \\
\text { more spacecraft and over more } \\
\text { missions } \\
\text { - Common spares and logistics } \\
\text { support reduce cost }\end{array}$ & $\begin{array}{l}\text { - Validated and heritage } \\
\text { designs have low/known risk } \\
\text { - Easily replaceable (lower } \\
\text { consequence of failure) }\end{array}$ \\
\hline $\begin{array}{l}\text { Discrete Performance } \\
\text { Levels }\end{array}$ & $\begin{array}{l}\text { - Captures most of the benefit } \\
\text { of a continuously optimized } \\
\text { design }\end{array}$ & $\begin{array}{l}\text { - Design for low cost, not } \\
\text { optimized performance }\end{array}$ & $\begin{array}{l}\text { - Some excess capability } \\
\text { increases margins and lowers } \\
\text { risk }\end{array}$ \\
\hline Plug and Play & $\begin{array}{l}\text { - Easy to introduce higher } \\
\text { performance systems as they } \\
\text { become available } \\
\text { - Can incorporate best available } \\
\text { system latest in manufacturing } \\
\text { schedule }\end{array}$ & $\begin{array}{l}\text { Eliminating sub-system } \\
\text { interactions and dependencies } \\
\text { eliminates design changes in } \\
\text { one system impacting design of } \\
\text { others }\end{array}$ & $\begin{array}{l}\text { Eliminating sub-system } \\
\text { interactions and dependencies } \\
\text { lowers risk of entire system } \\
\text { development }\end{array}$ \\
\hline $\begin{array}{l}\text { Only form, fit and } \\
\text { function specified }\end{array}$ & & $\begin{array}{l}\text { - Reduce cost by not over- } \\
\text { specifying requirements } \\
\text { - Reduce cost by not constantly } \\
\text { changing requirements }\end{array}$ & $\begin{array}{l}\text { - Reduce risk of missing } \\
\text { schedule due to changing or } \\
\text { over-specification of } \\
\text { requirements }\end{array}$ \\
\hline \multicolumn{4}{|l|}{ Versatility } \\
\hline $\begin{array}{l}\text { Accommodate variety } \\
\text { of launch vehicle } \\
\text { packaging options }\end{array}$ & $\begin{array}{l}\text { - Can use packaging and launch } \\
\text { vehicle integration to minimize } \\
\text { launch load impact on system } \\
\text { design, decreasing mass }\end{array}$ & $\begin{array}{l}\text { - Choose launch vehicle (LV) } \\
\text { based on price } \\
\text { - Decrease insurance cost based } \\
\text { on LV reliability }\end{array}$ & $\begin{array}{l}\text { - Choose launch vehicle based } \\
\text { on reliability } \\
\text { - Move payload to different } \\
\text { launch vehicle if initial one has } \\
\text { failure }\end{array}$ \\
\hline $\begin{array}{l}\text { Reconfigurable on orbit } \\
\text { for new mission or } \\
\text { application }\end{array}$ & & $\begin{array}{l}\text { - Mutli-functional systems can } \\
\text { assume roles of damaged or } \\
\text { failed ones } \\
\text { - Save cost by reusing systems } \\
\text { that still have service life }\end{array}$ & $\begin{array}{l}\text { - Reduce risk by using } \\
\text { components and systems that } \\
\text { have already been proven }\end{array}$ \\
\hline $\begin{array}{l}\text { Capability for } \\
\text { disassembly and } \\
\text { reassembly }\end{array}$ & $\begin{array}{l}\text { - Reduce mass; design for in- } \\
\text { service, not launch loads }\end{array}$ & $\begin{array}{l}\text { Instead of reducing mass, } \\
\text { reduce operating margin, } \\
\text { extend life of system }\end{array}$ & $\begin{array}{l}\text { Instead of reducing mass, } \\
\text { increase margin of safety and } \\
\text { reduce risk }\end{array}$ \\
\hline Upgradeable & $\begin{array}{l}\text { - Introduce increased and/ or } \\
\text { new capabilities as they } \\
\text { become available }\end{array}$ & $\begin{array}{l}\text { - Introduce increased and/or } \\
\text { new capabilities as they } \\
\text { become affordable } \\
\text { - Quickly enter system into } \\
\text { service - IOC, upgrade later }\end{array}$ & $\begin{array}{l}\text { - Reduce risk do no wait until a } \\
\text { new technology is validated } \\
\text { - Reduce risk by not relying on } \\
\text { new technology that may not be } \\
\text { successfully developed }\end{array}$ \\
\hline Growable, scalable & $\begin{array}{l}\text { Can improve or upgrade } \\
\text { performance incrementally }\end{array}$ & $\begin{array}{l}\text { Minimize time (and cost) to } \\
\text { enter into service with Initial } \\
\text { Operating Capability (IOC), } \\
\text { add capability later }\end{array}$ & $\begin{array}{l}\text { Lower risk by validating in } \\
\text { service IOC capabilities, } \\
\text { making any corrections, before } \\
\text { adding capability }\end{array}$ \\
\hline \multicolumn{4}{|c|}{ Maintainability (in space, or on planetary surfaces) } \\
\hline Serviceable & $\begin{array}{l}\text { Reduce mass and complexity of } \\
\text { IOC by reducing number of } \\
\text { spares and redundant systems }\end{array}$ & $\begin{array}{l}\text { Extending service life reduces } \\
\text { need to buy and launch } \\
\text { new/replacement systems }\end{array}$ & $\begin{array}{l}\text { Routine servicing reduces } \\
\text { likelihood of failure }\end{array}$ \\
\hline Repairable & & $\begin{array}{l}\text { - Reduce cost for ultra-high } \\
\text { reliability } \\
\text { - Reduce number of redundant } \\
\text { systems }\end{array}$ & $\begin{array}{l}\text { - Reduce consequence of } \\
\text { failure to mission and program }\end{array}$ \\
\hline
\end{tabular}


One objective of the current research is to develop metrics for assessing the modular attributes listed in Table 1 against the mission/spacecraft system Initial Operating Capability (IOC) and In-Service life-cycle approaches. The four approaches considered are: 1) pre-launch integration (where integrated systems are defined to be those that are not designed for any on-orbit assembly or dis-assembly) - PI; 2) pre-launch assembly (systems that feature interfaces designed for on-orbit assembly and dis-assembly, but the interfaces are assembled prior to launch) - PA; 3) on-orbit assembly to attain the spacecraft IOC configuration - OOA; and, 4) sustained in-space operations (that includes servicing, component replacement, component repair, etc.) - SO. Although a space system or spacecraft can include one or more of all of these approaches, certain specific combinations, as described in table 3, have generally been implemented, or would be practical in the design and operational concept. Most currently built spacecraft and satellites consist entirely of pre-integrated components (first line in the table) and have no provisions for sustainability. This is the only practical approach since no infrastructure or capability exists in space to provide any services. Perhaps the simplest example of an application that is pre-integrated but designed for sustained operations (line two in the table) is a spacecraft that can be re-fueled on orbit. The Hubble Space Telescope represents a third practical combination consisting of pre-integration, a limited amount of pre-assembly and sustained operations (Pfarr, 1997). Although most of the telescope was pre-integrated, it was designed with access doors and covers and instruments and components that were pre-assembled before launch to allow for maintenance and instrument/module replacement and repair. The Assembly Concept for Construction of Erectable Space Structure (ACCESS) was a truss construction experiment flown on the Orbiter Atlantis on November 26, 1985 (Heard, 1986). Much of the hardware was pre-integrated before launch to form joint and strut elements, which were then efficiently packaged and assembled on orbit. The experiment also demonstrated hardware design features that supported sustained operations, such as truss strut removal and replacement, truss dis-assembly, and utility line attachment. Two examples are given for spacecraft that incorporate all four life-cycle approaches; the ISS (which is in service), and the SETV (Wingo, 2006) that serves as the focus application in this paper.

TABLE 3. Practical Mission Life Cycle Approaches and Applications.

\begin{tabular}{|c|c|c|c|c|}
\hline \multicolumn{4}{|c|}{ Mission Life Cycle Approach: Practical Combinations } & \multirow[b]{2}{*}{ Example and Comments } \\
\hline $\begin{array}{l}\text { Pre-Integration } \\
\text { (PI) }\end{array}$ & $\begin{array}{c}\text { Pre-Assembled } \\
\text { (PA) }\end{array}$ & $\begin{array}{c}\text { On-Orbit } \\
\text { Assembled (OOA) }\end{array}$ & $\begin{array}{c}\text { Sustained } \\
\text { Operations (SO) }\end{array}$ & \\
\hline $\mathbf{X}$ & & & & $\begin{array}{l}\text { Implementation for most current } \\
\text { satellites and spacecraft }\end{array}$ \\
\hline $\mathbf{X}$ & & & $\mathbf{X}$ & $\begin{array}{l}\text { In this implementation, only a } \\
\text { limited amount of sustaining } \\
\text { operations could be performed }\end{array}$ \\
\hline $\mathbf{X}$ & $\mathbf{X}$ & & $\mathbf{X}$ & Hubble Space Telescope \\
\hline $\mathbf{X}$ & & $\mathbf{X}$ & $\mathbf{X}$ & ACCESS Truss Assembly \\
\hline $\mathbf{X}$ & $\mathbf{X}$ & $\mathbf{X}$ & $\mathbf{X}$ & ISS, SETV \\
\hline
\end{tabular}

In Table 4, the modular attributes are listed, and an " $\mathrm{X}$ " used to indicate which life cycle approach the attribute can potentially benefit. The associated metrics can be applied at the spacecraft or space platform level, the mission level (where a mission could have many replications of a single spacecraft, or many different spacecraft), and at the architecture level (that is composed of multiple missions). For affordable and sustainable architectures, missions and spacecraft, the metrics should be relevant to life cycle cost, and include considerations for performance and risk. In this context, the metrics listed in table 4 should be used in conjunction with costs and cost rates for each item. Thus, the metrics in and of themselves do not result in any sort of value judgment until combined in a merit function that measures cost.

There is some difficulty in developing measures, or metrics, that are actually relevant to the desired beneficial features, or attributes, and exercising them at a high enough level to correctly capture all effects. One might argue that cost is the only relevant metric, especially in the context of an Exploration Program that is emphasizing affordability and sustainability. In this case, where a long-term and sustainable program is necessary, it is the total life-cycle cost that should be assessed as competing architectures, missions, and spacecraft concepts are being evaluated and selected. In the past, focusing on one term of the life-cycle cost equation, such as launch or development costs, leads to systems designs that suffer high operations, maintenance and repair costs. In this context, space systems designed for modular assembly may incur a slight performance penalty, increased mass to incorporate features that enable servicing and repair, but realize large benefits in reduced cost to service and repair, and reduced risk, because servicing and repair are built into the system. Also, developing on orbit infrastructure and 
agent capabilities would incur development costs not associated with a non-modular assembly approach, but in a sustainable program, where these systems would be resources used for many different systems and spacecraft, their costs would not be borne by one mission, but rather, amortized over many missions, and should be treated as a capital investment with a break-even point for return on investment. When assessing risk, the probability of failure is important, but it is the consequence of failure that is paramount, and where the modular assembly approach will have substantial benefit. If modular systems became common (approaching a commodity), then the consequence of losing a payload during launch, or failure on orbit, is greatly reduced because the incremental cost of purchasing the next module can be low. Similarly, the consequence of failure increases as the launch vehicle mass capability, and thus the amount of payload it can carry, increases. Modular assembly spacecraft design would provide a means of reducing the consequence of launch failure to an acceptable level by launching the spacecraft in increments that each would represent an acceptable loss if there was a launch failure.

TABLE 4. Life Cycle Phases and Metrics ( $\mathbf{X}=$ can potentially benefit).

\begin{tabular}{|c|c|c|c|c|c|}
\hline \multirow[t]{2}{*}{ Attribute } & \multicolumn{4}{|c|}{ Life Cycle Approach } & \multirow{2}{*}{$\begin{array}{c}\text { Metrics: Applied at spacecraft, mission or architecture } \\
\text { level }\end{array}$} \\
\hline & PI & PA & OOA & SO & \\
\hline \multicolumn{6}{|l|}{ Standardization } \\
\hline Standard Interfaces & $\mathbf{X}$ & $\mathbf{X}$ & $\mathbf{X}$ & $\mathbf{X}$ & $\begin{array}{l}\text { - Number of different interfaces } \\
\text { - Number of replications for each } \\
\text { - Total number of connections } \\
\text { - Number of simultaneous connections required } \\
\text { - Precision required } \\
\text { - Time per connection } \\
\text { - Number or amount of unique tools, agents or infrastructure } \\
\text { required }\end{array}$ \\
\hline Standard Modules & $\mathbf{X}$ & $\mathbf{X}$ & $\mathbf{X}$ & $\mathbf{X}$ & $\begin{array}{l}\text { - Number of different modules } \\
\text { - Number of replications for each } \\
\text { - Module cost } \\
\text { - Mass \& moment of inertia } \\
\text { - Volume and dimensions }\end{array}$ \\
\hline Discrete Performance Levels & $\mathbf{X}$ & $\mathbf{X}$ & $\mathbf{X}$ & $\mathbf{X}$ & $\begin{array}{l}\text { - Overall performance range } \\
\text { - Number of levels } \\
\text { - Spacing between levels }\end{array}$ \\
\hline Plug and Play & $\mathbf{X}$ & $\mathbf{X}$ & $\bar{X}$ & $\mathbf{X}$ & $\begin{array}{l}\text { >Validation and verification resources: } \\
\text { - Time } \\
\text { - Agents } \\
\text { - Test equipment }\end{array}$ \\
\hline $\begin{array}{l}\text { Only form, fit and function } \\
\text { specified }\end{array}$ & $\mathbf{X}$ & $\bar{X}$ & $\bar{X}$ & $\mathbf{X}$ & - Level at which requirements specified \\
\hline \multicolumn{6}{|l|}{ Versatility } \\
\hline $\begin{array}{l}\text { Accommodate variety of } \\
\text { launch vehicle packaging } \\
\text { options }\end{array}$ & & & $\mathbf{X}$ & $\mathbf{X}$ & $\begin{array}{l}\text { - Size of modules, orbital replacement units (ORUs) } \\
\text { - Mass of modules } \\
\text { - ORUs and spares: amenable to rapid launch response }\end{array}$ \\
\hline $\begin{array}{l}\text { Reconfigurable on orbit for } \\
\text { new mission or application }\end{array}$ & & $\mathbf{X}$ & $\mathbf{X}$ & $\mathbf{X}$ & $\begin{array}{l}\text { - Number of applicable missions } \\
\text { - Number of different geometries } \\
\text { - Number of disassemblable interfaces }\end{array}$ \\
\hline $\begin{array}{l}\text { Capability for disassembly } \\
\text { and reassembly }\end{array}$ & & $\mathbf{X}$ & $\mathbf{X}$ & $\mathbf{X}$ & $\begin{array}{l}\text { > Resources required*: } \\
\text { - Time used for task } \\
\text { - Number of operations/steps } \\
\text { - Degree of repetition in steps } \\
\text { - Support infrastructure required } \\
\text { - Number of agents and types } \\
\text { - Types and number of tools required } \\
\text { - Precision of operations required } \\
\text { - Type and amount of utilities }\end{array}$ \\
\hline Upgradeable & & $\mathbf{X}$ & $\mathbf{X}$ & $\mathbf{X}$ & $\begin{array}{l}\text { - Availability of upgrades } \\
\text { - Resources required* (see list) } \\
\text { - Operations performed in-service or at depot }\end{array}$ \\
\hline Growable, scaleable & & $\mathbf{X}$ & $\mathbf{X}$ & $\mathbf{X}$ & $\begin{array}{l}\text { - Number of replications possible without redesign } \\
\text { - Size range of growth without system redesign }\end{array}$ \\
\hline \multicolumn{6}{|c|}{ Maintainability (in space, or on planetary surfaces) } \\
\hline Serviceable & & $\mathbf{X}$ & $\mathbf{X}$ & $\mathbf{X}$ & $\begin{array}{l}\text { - Number of serviceable items } \\
\text { - Resources required* (see list) }\end{array}$ \\
\hline Repairable & & $\mathbf{X}$ & $\mathbf{X}$ & $\mathbf{X}$ & $\begin{array}{l}\text { - Availability of ORUs, spares, etc. } \\
\text { - Number of different spares required } \\
\text { - Resources required* (see list) } \\
\text { - Location for performing operations (in-service or at depot) }\end{array}$ \\
\hline
\end{tabular}




\section{THREE MODULAR LEVELS FOR A SOLAR ELECTRIC TRANSFER VEHICLE CONCEPT}

The primary objective of the MALSP Project (Collins, 2006a) is to demonstrate the benefits and feasibility of modular spacecraft design and approaches through systems concept studies, targeted hardware development and realistic assembly scenario testing and validation. In order to focus the project's efforts, solar power applications (collecting platforms and transport vehicles) were reviewed and a SETV chosen as a target application .

\section{SETV System Description}

The purpose of the SETV is to transfer cargo from Low Earth Orbit (LEO) to Low Lunar Orbit (LLO) and other locations as specified in the Vision for Space Exploration. The SETV configuration developed by the team, as shown in figure 1a, seeks to incorporate all of the modular attributes that are listed in Table 1. The tug uses photovoltaic solar arrays to generate electricity, which is used to power Hall Effect ion thrusters. Xenon is baselined as the propellant for the ion thrusters. Details of various aspects of the SETV design are given in Wingo (2006), Woodcock (2006), Collins (2006b) and Mikulas (2006). At its largest size, the tug develops approximately $450 \mathrm{kw}$ of power, and can transport a 60 metric ton payload from LEO to LLO and return in less than one year. The SETV is designed using technologies that are currently available, or will be available no later than 2008, with an initial operating capability targeted for 2012. Because of its large size and mass, the SETV requires multiple launches and some amount of on-orbit assembly, with the amount depending on the specific design implementation. The SETV is also designed for a service life of 30 years, with regularly scheduled servicing and maintenance. For example, the SETV must be refueled after every roundtrip and the solar arrays and Hall ion Thrusters are both designed to be replaced at 4-year intervals.

General design features that significantly contributed to the SETV configuration definition include: 1) the system be composed of modular units that can be replaced in situ; 2) the configuration be amenable to a variety of design implementations and system decomposition, allowing it to be packaged on a variety of launch vehicles; and, 3) the launched components be capable of being assembled on orbit using both human and robotic resources and capabilities. Operational requirements have been developed for the SETV, along with requirements for all of the major systems such as control, electrical power, communications, data, structures, thermal management, propulsion and payload integration (Wingo, 2006). The configuration layout and definition shown in figure 1a meets all of the system level requirements.

\section{Modular Assembly Scenario Descriptions}

The degree to which many of the modular attributes and detailed sub-attributes (see Table 1) satisfy requirements depends on details of the design implementation. For modular assembly, the design implementation, in turn, depends on assumptions about the level of modularity desired or incorporated into the spacecraft, the choice of launch vehicle, the on orbit operations capabilities assumed for agents, and the amount of on-orbit infrastructure and resources assumed. In order to assess the ideas developed in this paper, three different modular design implementations (representing three different levels of modular assembly) for packaging, launch, deployment and assembly were developed for the SETV. Routine servicing operations that must be accommodated for all three levels are; refueling after each round trip, thruster replacement every four years, and solar array replacement every four years. Based on these servicing and maintenance requirements, the following five standard locations for module-to-module assemblable/dis-assemblable interfaces were defined for the SETV system (see figure 3): Type 1, keel truss-to-solar array (SA) support truss; Type 2, SA support truss assemble/dis-assemble bay; Type 3, inboard SA-to-SA support truss; Type 4, outboard SA-to-SA support truss; and Type 5, thruster/PPU-to-SA support truss. These joint definitions are identical for all three modular assembly scenarios, with the difference being which are pre-assembled prior to launch, and which are assembled on orbit.

Three classes of evolvable expendable launch vehicles (EELVs) are also considered: heavy lift (represented by Atlas V-Heavy and Delta IV-Heavy) - EELV-H; medium lift (represented by Atlas V-Medium and Delta IV-Medium) EELV-M; and lite lift (represented by Delta II-Heavy) - EEVL-L. These three classes of launch vehicles offer a variety of mass and payload volume capabilities for packaging spacecraft modules for launch to orbit. For modular 
assembly scenarios that do not make use of pre-existing on-orbit infrastructure and facilities (ISS for example), each payload must also have an independent capability for maintaining a stable orbit and attitude control until the payload can operate as a self reliant spacecraft. For all three scenarios considered here, the SETV assembly location is at an altitude of $400 \mathrm{~km}$, and inclination of 51.6 degrees (ISS orbit). For assembly scenarios 1 and 2 (that do not use ISS resources) assembly is assumed to occur in the vicinity of ISS to minimize mission risk, i.e., in the event of any type of problem or failure, ISS resources could be used for emergencies. The launch vehicle type, in-space infrastructure, and agents used, along with advantages and disadvantages for each scenario are summarized in Table 5.
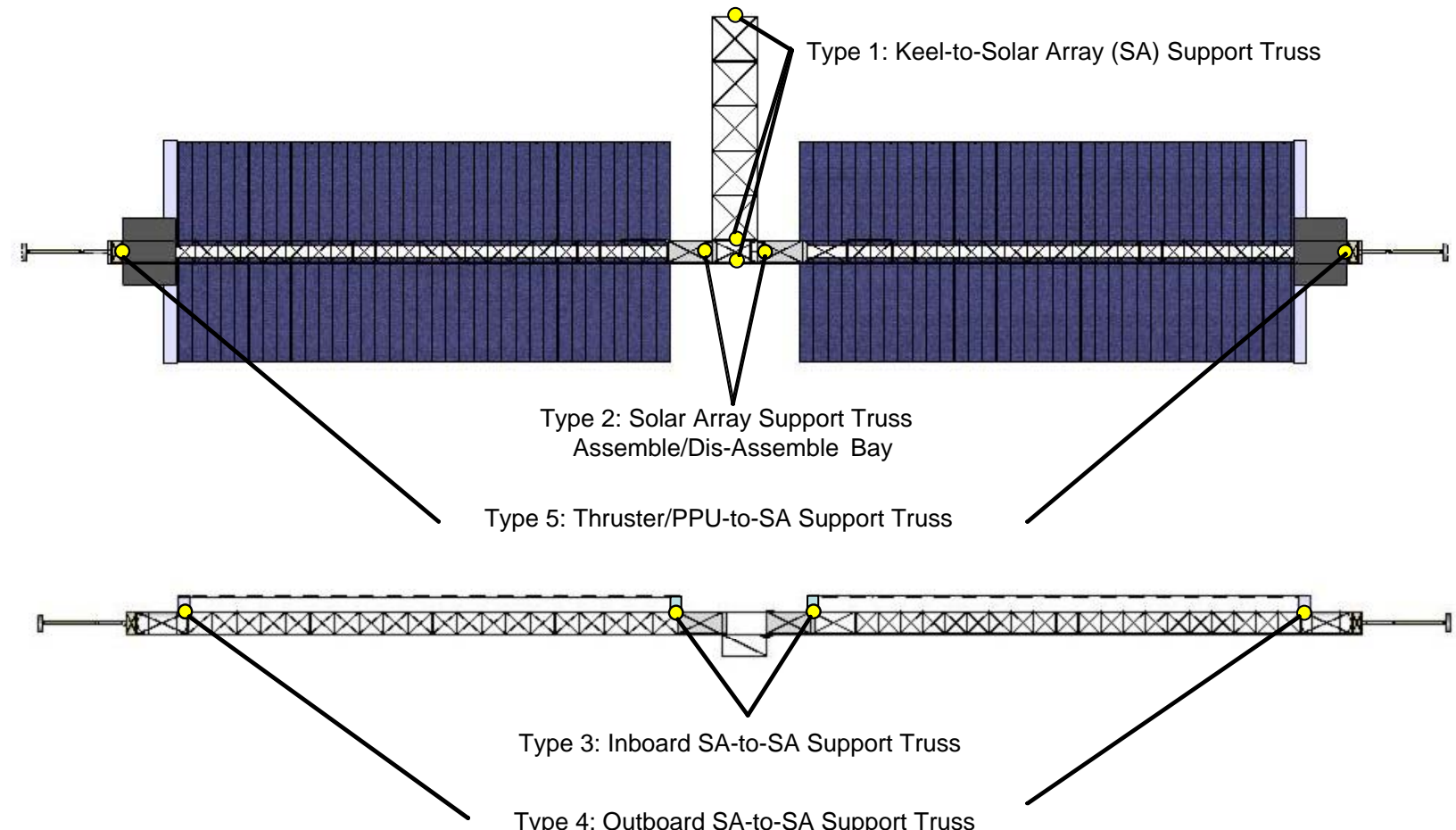

FIGURE 3. SETV Assemblable/Dis-Assemblable Interfaces.

The three modular assembly scenario interface types are shown in figure 4, where the yellow indicates an on-orbit assembled interface, and the coral indicates a pre-assembled interface. Modular Assembly Scenario 1, with interface types shown in figure 4a, seeks to minimize the use of any on-orbit resources, and most closely represents a status quo approach to entering a $450 \mathrm{kw}$-class SETV into service. In this scenario, the full $450 \mathrm{kw}$-class SETV is decomposed into two independent $225 \mathrm{kw}$-class SETV modules, which are launched separately on two EELV-Hs. Each module is pre-integrated and preassembled before launch and fully deployable on orbit without any assistance or intervention from agents. Each module must also be a fully functional spacecraft following deployment. The first module includes systems that enable rendezvous and berthing with payloads, and these systems are used to rendezvous with the second module and berth it to complete the spacecraft. The major assembly involves mechanically connecting the two modules at their keel beams following berthing. This is accomplished autonomously using the on-board Payload Berthing and Servicing Arms (PBSA). The scenarios described here outline the functions of the PBSA, but options for its implementation, in the form of a space crane, Space Station Remote Manipulator System (SSRMS) - type arm, spiderbot, etc. await definition and study. Further details on packaging and deployment concepts for modular assembly scenario 1 are contained in Collins (2006b).

In Modular Assembly Scenario 2 (see figure 4b), the SETV is decomposed into several modules for each launch to allow for more launch vehicle packaging versatility and reduce some of the very complex packaging and deployment constraints imposed on the system by scenario 1 . The first launch, on a EELV-H, is composed of a single-fold deployable keel beam module, eight $25 \mathrm{kw}$ power/propulsion (wing) modules and one PBSA integrated with the keel beam. All of the modules are integrated into an isogrid platform that is attached to the payload integration ring on the EELV. Once on-orbit, the keel beam deploys, then the PBSA releases each power/propulsion 
module from the isogrid platform, berths and mechanically attaches it to the keel beam and then the module is autonomously deployed. For every pair of deployed wings, a power connection is required across the keel beam. The second launch also uses a EELV-H, and the payload consists of eight more power/propulsion modules, a second PBSA, and any spares or payloads of opportunity that can be added (until the launch vehicle mass limit is reached). The spacecraft assembled as a result of the first launch, rendezvous to the second payload, the PBSA- 1 grapples the second payload and berths it to the free end of the keel beam and then proceeds to attach each of the eight power/propulsion modules. The modules are autonomously deployed after all have been attached to the keel beam.

TABLE 5. Three SETV Modular Assembly Scenarios.

\begin{tabular}{|c|c|c|}
\hline $\begin{array}{c}\text { Modular Assembly } \\
\text { Scenario }\end{array}$ & Advantages & Disadvantages \\
\hline $\begin{array}{l}\text { 1. Two } 225 \text { kw-class } \\
\text { Modules } \\
\text { Launch: } 2 \text { EELV-Hs } \\
\text { In-Space Infrastructure: } \\
\text { the first SETV module } \\
\text { serves as infrastructure } \\
\text { Agents: } 2 \text { Payload } \\
\text { Berthing and Servicing } \\
\text { Arms (one launched on } \\
\text { each flight) }\end{array}$ & $\begin{array}{l}\text { - Minimizes initial amount of in-space operations } \\
\text { to achieve IOC } \\
\text { - Requires no pre-existing infrastructure } \\
\text { - Can be assembled in any orbit }\end{array}$ & $\begin{array}{l}\text { - Risk that entire module will not package in } \\
\text { EELV-H as design matures } \\
\text { - Very complex packaging scheme } \\
\text { - Very complex deployment - driven by } \\
\text { packaging constraints, leading to high degree } \\
\text { of pre-integration } \\
\text { - May be more difficult to service because of } \\
\text { high degree of pre-integration } \\
\text { - Large number of unique deployment } \\
\text { devices (hinges, motors, etc.) } \\
\text { - May require additional attitude control and } \\
\text { power storage systems to maintain stability } \\
\text { before module can be fully deployed }\end{array}$ \\
\hline $\begin{array}{l}\text { 2. Keel Module and } \\
\text { sixteen power/ propulsion } \\
\text { modules } \\
\text { Launch: } 2 \text { EELV-Hs } \\
\text { In-Space Infrastructure: } \\
\text { the deployed first tug } \\
\text { module serves as } \\
\text { infrastructure } \\
\text { Agents: } 2 \text { Payload } \\
\text { Berthing and Servicing } \\
\text { Arms (one on each flight) }\end{array}$ & $\begin{array}{l}\text { - Less deployment complexity (cost, risk, } \\
\text { integration, etc.) compared to scenario } 1 \\
\text { - PBSA can serve as deployment aid (eliminating } \\
\text { all deployment motors, cables and some } \\
\text { mechanisms) } \\
\text { - Reduces duplication of field joints with pre- } \\
\text { integrated deployable joints } \\
\text { - Decomposition provides option for modules to be } \\
\text { packaged on EELV-Ms and EELV-Ls (increases } \\
\text { number of launches, not necessarily launch cost) } \\
\text { - Easier to package agents }\end{array}$ & $\begin{array}{l}\text { - Potential duplication of stabilizing system } \\
\text { for each of a large number of launch } \\
\text { packages } \\
\text {-May require additional attitude control and } \\
\text { power storage systems to maintain stability } \\
\text { before sufficient arrays and thrusters can be } \\
\text { deployed to provide control }\end{array}$ \\
\hline $\begin{array}{l}\text { 3. Eight Keel Modules, } \\
\text { Sixteen array/propulsion } \\
\text { support trusses (with } \\
\text { integrated fuel tanks), } \\
\text { Sixteen Propulsion } \\
\text { modules and Sixteen solar } \\
\text { array modules } \\
\text { Launch: } 8 \text { EELV-Ls } \\
\text { In-Space Infrastructure: } \\
\text { ISS (or other assembly } \\
\text { facility), Simple assembly } \\
\text { jig that Supports keel beam } \\
\text { Agents: SSRMS, } 2 \text { PBSAs }\end{array}$ & $\begin{array}{l}\text { - All modules can be optimized for in-service } \\
\text { operability and ease of servicing and repair } \\
\text { - Launch vehicle packaging has least impact on } \\
\text { system design } \\
\text { - Can use ISS resources, especially power, attitude } \\
\text { control, EVA (for emergencies) } \\
\text { - PBSA can serve as deployment aid (eliminating } \\
\text { all deployment motors, cables and some } \\
\text { mechanisms) } \\
\text { - Less deployment complexity (cost, risk, } \\
\text { integration, etc.) compared to scenarios } 1 \text { and } 2 \\
\text { - Allows for pure assemblable joints at all } \\
\text { interfaces (reducing duplication and complexity) } \\
\text { - Allows for incremental build up and verification, } \\
\text { with many intervention points, reducing risk } \\
\text { - Allows solar array fold height to be optimized } \\
\text { - Allows human intervention for unforeseen } \\
\text { problems }\end{array}$ & $\begin{array}{l}\text { - Must conform to ISS operating restrictions, } \\
\text { resource availability and other constraints }\end{array}$ \\
\hline
\end{tabular}

Modular Assembly Scenario 3 (figure 4c) is specifically designed to use on orbit infrastructure and resources (in this case those available on the ISS) and only EELV-L class transportation to LEO. This scenario decomposes the SETV to the level where known items requiring periodic replacement would be assembled on orbit (in particular, the solar arrays and the ion thrusters). A direct consequence of decomposing the SETV to incorporate this high degree of modular assembly is this scenario provides the greatest decoupling of module packaging from launch vehicle constraints (i.e., it provides the most versatility for launch). In this scenario, each launch uses a EELV-L, and each package consists of a single-fold sequentially deployable keel beam truss, two deployable solar array/thruster support trusses (including pre-assembled propellant tanks), two solar array wing packages, and two pre-assembled ion thruster/PPU assemblies. In addition, the first and the second flights carry PBSAs, the first of which acts as a deployment aid for all required deployments. Each launch package would rendezvous with the ISS and the Space 
Station Remote Manipulator System (SSRMS) berths the package with the ISS at the designated assembly worksite. Each assembly sequence is identical for the eight payloads; the PBSA deploys the keel beam section, attaches the two solar array/thruster support trusses to the keel, deploys each of the trusses, attaches each of the propulsion modules to the trusses, attaches and deploys each of the solar array packages, and cleans up the worksite.

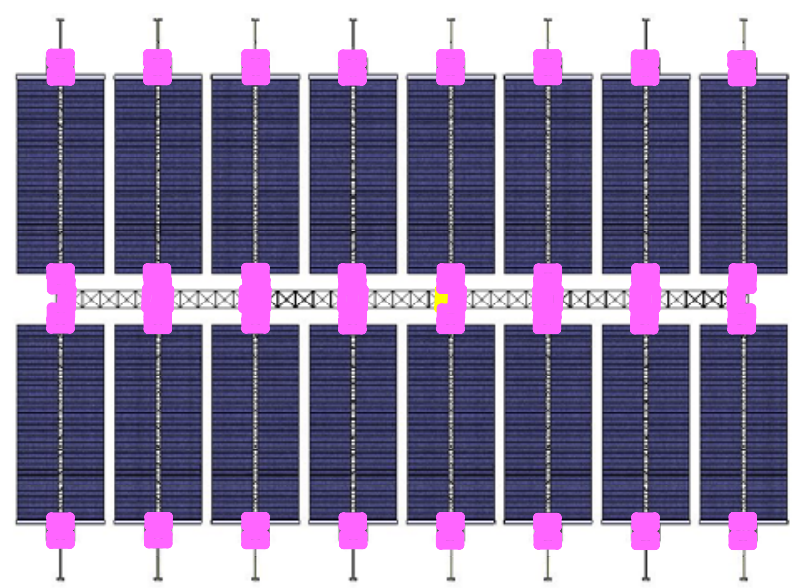

(a) Scenario 1.

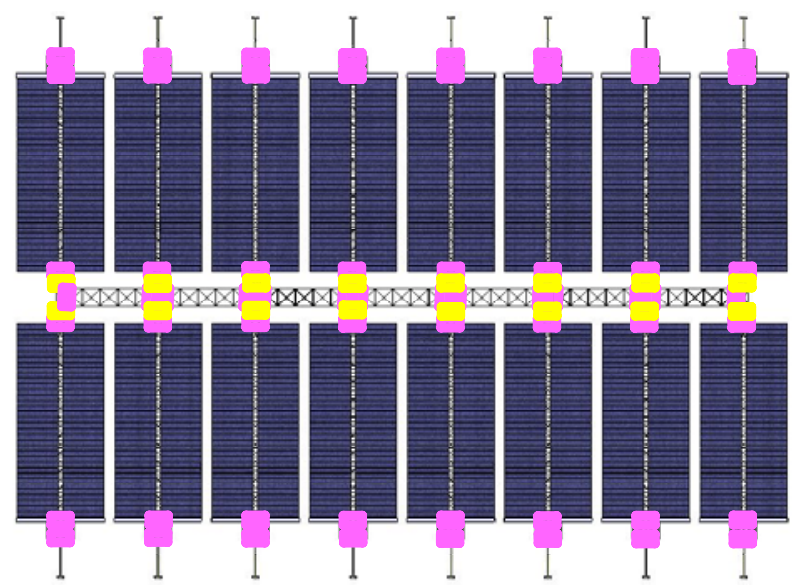

(b) Scenario 2.
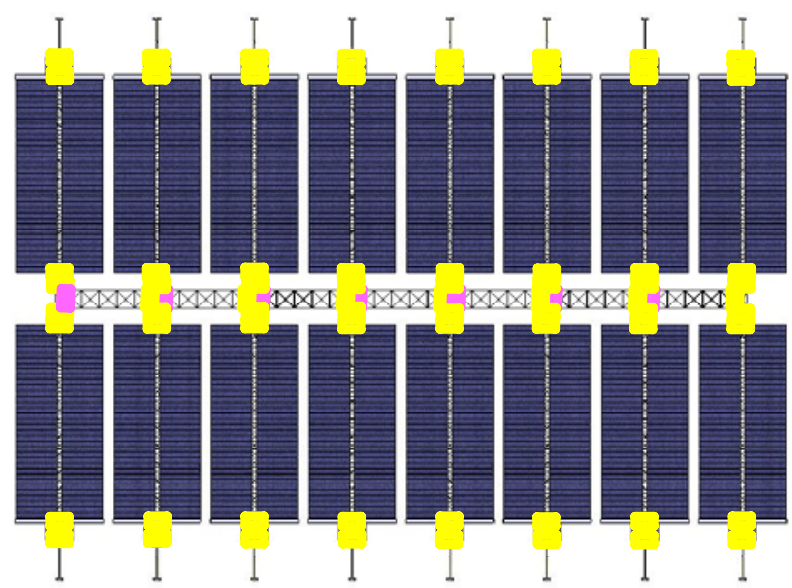

(c) Scenario 3.

FIGURE 4. Interface Types for Three Modular Assembly Scenarios. 


\section{Assessment of 3 SETV Modularity Levels}

The three modular assembly scenarios described in the previous section have been developed to emphasize different levels of modularity, and as a consequence, the amount and types of in-space operations required. All three options have advantages and disadvantages, many of which are given in table 5 . The next step in generating a value judgment about the three options, i.e., selecting which is the "best" modular assembly scenario, is applying the modularity metrics that have been proposed in table 4 to the three scenarios and determining the value, degree of implementation, degree of compliance, etc. to each metric. Table 6 gives an example of evaluating the metrics for standard interfaces (number of different interfaces and number of replications for each) and standard modules (number of different modules and number of replications of each) for the three modular assembly scenarios. Note that for all three scenarios, the total number of assemblable/disassemblable joints is 78 and that the three scenarios span a wide range of options for in-space operations, as reflected in the distribution of OOA versus PA interfaces for each. Similarly, a wide range in packaging versatility and possible launch vehicle choices can be inferred from the span of total number of OOA modules for the three scenarios.

TABLE 6. Example of Metrics Assessment For SETV Three Modular Assembly Scenarios.

\begin{tabular}{|c|c|c|c|}
\hline \multirow[b]{2}{*}{ Metric } & \multicolumn{3}{|c|}{ Modular Assembly Scenario } \\
\hline & 1 & 2 & 3 \\
\hline \multicolumn{4}{|l|}{ Standard Interfaces } \\
\hline Number of Different Types: OOA & 1 & 1 & 5 \\
\hline Number of Different Types: PA & 4 & 4 & 1 \\
\hline Number of Occurrences: OOA & 1 & 16 & 71 \\
\hline - Type 1 & 1 & - & 7 \\
\hline - Type 2 & - & 16 & 16 \\
\hline - Type 3 & - & - & 16 \\
\hline - Type 4 & - & - & 16 \\
\hline - Type 5 & - & - & 16 \\
\hline Number of Occurrences: PA & 77 & 62 & 7 \\
\hline - Type 1 & 13 & 14 & 7 \\
\hline - Type 2 & 16 & - & - \\
\hline - Type 3 & 16 & 16 & - \\
\hline - Type 4 & 16 & 16 & - \\
\hline - Type 5 & 16 & 16 & - \\
\hline \multicolumn{4}{|l|}{ Standard Modules } \\
\hline Total Number of OOA Modules & 2 & 17 & 55 \\
\hline Number of Different OOA Modules & 1 & 2 & 4 \\
\hline Number of Occurrences of Each & $\begin{array}{l}2 \text { (225 kw-class SETV } \\
\text { modules) }\end{array}$ & $\begin{array}{l}\text { - } 1 \text { (keel) } \\
-16 \text { (power \& } \\
\text { propulsion) }\end{array}$ & $\begin{array}{l}-7 \text { (keel) } \\
-16 \text { (SA support truss, } \\
\text { includes tank and } \\
\text { radiator) } \\
-16 \text { (SA) } \\
-16 \text { (thruster/PPU) }\end{array}$ \\
\hline
\end{tabular}

Before any value judgment can be made, assessments would have to be made for all of the metrics. After all of the assessment data has been generated and compiled, the metrics listed in table 4 can be used to construct a Figure Of Merit (FOM) that reflects the program manager's, customer's, stake-holder's, etc. (whoever is making the decision) particular desires and requirements for the program or mission. The decision maker also assigns the weights to each metric making up the FOM to reflect their specific emphasis, needs and requirements. By varying the weights for each term in the FOM, as well as the metric terms contained in the FOM, the decision maker can perform parametric studies to determine the importance of various metrics to the option chosen, as well as the sensitivity of a particular option to changes in the metrics. Ideally, the figure of merit would relate to minimizing life cycle costs if the most affordable and sustainable option is desired.

\section{CONCLUSIONS}

A comprehensive modular assembly system model has been proposed that extends the art from modular hardware, to include in-space assembly, servicing and repair and it's critical components of infrastructure, agents and assembly operations. Included is a set of modular assembly attributes that allow the degree of modularity for a system to be defined and assessed so that competing concepts can be compared. Benefits of modular assembly have been 
identified and a set of metrics defined that extends the art beyond the traditional measures of performance, with a focus on including criteria that allow life-cycle mission costs to be used as a figure of merit (and include all substantive terms that have an impact on the evaluation). This model is general and can be applied to, and used to evaluate competing options for both in-space and planetary surface based exploration systems.

The modular assembly approach was used as a basis for developing a Solar Electric Transfer Vehicle (SETV) concept. The resulting vehicle configuration features a great deal of versatility with respect to launch vehicle payload-class options, as well as the degree of on-orbit assembly operations required (giving a wide range of possible levels of cost and risk). Three modular assembly scenarios were developed for the SETV, all of which allow for long service life and ease of in-space servicing, repair and module upgrades. The modular assembly approach also allows the SETV to be entered into service much earlier than competing conventional configurations by using existing and near-term technology, while having the capability for upgrading modules as better performing technology is developed and becomes affordable. The SETV design example demonstrated that the degree of modularity is a direct consequence of the number, types and locations of modular interfaces, and is highly driven by requirements for servicing, maintenance and repair and to a lesser degree, launch vehicle packaging. Perhaps most important is to have interfaces that are designed to be easily assembled and dis-assembled. Doing so results in a great deal of versatility in accommodating different launch vehicle payload capabilities, allowing for modules to be either pre-assembled before launch or assembled on orbit, without changing the space vehicle design. Thus, modular assembly can be incorporated into space vehicle design regardless of the existence or need for any in-space operations capabilities, allowing for the space vehicle to benefit from modular attributes in anticipation of evolving capabilities.

\section{REFERENCES}

Collins, T., Dorsey, J., and Doggett, W., "Innovative Modular Design of Exploration Spacecraft, with Application to SolarElectric Transport Vehicles: A Project Overview,” in these proceedings of Space Technology and Applications International Forum (STAIF-2006), edited by M. El-Genk, American Institute of Physics, Melville, New York, 2006a.

Collins, T., Dorsey, J., Doggett, W., and Mikulas, M., "Modular Solar Electric Tug Spacecraft Structural Definition, Including Dynamic Analysis, Sizing, Packaging, Deployment and Assembly," in these proceedings of Space Technology and Applications International Forum (STAIF-2006), edited by M. El-Genk, American Institute of Physics, Melville, New York, 2006b.

Enright, J., Jilla, C., and Miller, D., “Modularity and Spacecraft Cost,” Journal of Reducing Space Mission Cost, Volume 1, 133158, (1998).

Esper, J., "Modular, Adaptive, Reconfigurable Systems: Technology for Sustainable, Reliable, Effective, and Affordable Space Exploration,” in proceedings of Space Technology and Applications International Forum (STAIF-2005), edited by M. ElGenk, AIP Conference Proceedings 746, Melville, New York, 2005, pp. 1033-1043.

Heard, W., Watson, J., Ross, J., Spring, S., and Cleave, M., "Results of the ACCESS Space Construction Shuttle Flight Experiment,” Copyright 1986, American Institute of Aeronautics and Astronautics, Inc., AIAA Paper No. 86-1186-CP.

Mikulas, M., Collins, T., Doggett, W., Dorsey, J., and Watson, J., “Truss Performance and Packaging Metrics,” in these proceedings of Space Technology and Applications International Forum (STAIF-2006), edited by M. El-Genk, American Institute of Physics, Melville, New York, 2006.

Pfarr, B., Ochs, W., Leibee, J., and Fatig, C., “Operations Lessons Learned From The Hubble Space Telescope First and Second Servicing Missions,” Copyright 1997, American Institute of Aeronautics and Astronautics, Inc., AIAA-97-3933.

Troutman, P., Mazanek, D., Stillwagen, F., Antol, J., et.al., “Orbital Aggregation and Space Infrastructure Systems (OASIS),” presented at the $53^{\text {rd }}$ International Astronautical Congress, The World Space Congress - 2002, 10 - 19 October, 2002, Houston, TX, IAC-02-IAA.13.2.06.

Wingo, D., Woodcock, G., Dorsey, J., and Doggett, W., "System Definition and Mission Implementation of a Modular Cis-Lunar Solar Electric Tug," in these proceedings of Space Technology and Applications International Forum (STAIF-2006), edited by M. El-Genk, American Institute of Physics, Melville, New York, 2006.

Woodcock, G. and Wingo, D., "Flight Mechanics and Control Requirements for a Modular Solar Electric Tug Operating in Earth-Moon Space,” in these proceedings of Space Technology and Applications International Forum (STAIF-2006), edited by M. El-Genk, American Institute of Physics, Melville, New York, 2006. 